\title{
A Philosophy of Physical Education Oriented toward the Game as an Object. Showing the Inexhaustible Reality of Games through Bernard Suits' Theory
}

\section{Wenceslao Garcia-Puchades \& Oscar Chiva-Bartoll}

To cite this article: Wenceslao Garcia-Puchades \& Oscar Chiva-Bartoll (2020) A Philosophy of Physical Education Oriented toward the Game as an Object. Showing the Inexhaustible Reality of Games through Bernard Suits' Theory, Sport, Ethics and Philosophy, 14:2, 192-205, DOI: 10.1080/17511321.2019.1630476

To link to this article: https://doi.org/10.1080/17511321.2019.1630476

册Published online: 11 Jun 2019.

Submit your article to this journal $₫$

山ll Article views: 54

Q View related articles $\sqsubset$

View Crossmark data $[\pi$ 


\title{
A Philosophy of Physical Education Oriented toward the Game as an Object. Showing the Inexhaustible Reality of Games through Bernard Suits' Theory
}

\author{
Wenceslao Garcia-Puchades (iD) and Oscar Chiva-Bartoll (iD ${ }^{\mathrm{b}}$ \\ aFacultat de Magisteri, Didactica Expresión Musical, Plastica y Corporal, Universitat de Valencia, Valencia, \\ Spain; 'bepartamento de Educación y Didácticas Específicas, Universitat Jaume I, Castello de la Plana, \\ Spain
}

\begin{abstract}
Although a large number of theories justify the presence of games in school, all of them converge in two of the educational functions described by Biesta, socialization and qualification. In contrast to this instrumental educational approach, the present article aims to develop the bases for a philosophy of physical education (PE) oriented toward the game as an object. This proposal is supported by Suits' theory of games and the object-oriented philosophy (OOP) introduced by Harman. The text presents a justification for games in the school setting by defending its intrinsic value. First, the instrumentalist justifications for games are presented in order to establish the state of the art. Second, an explanation is provided about the degree to which the object-oriented philosophy can complement these justifications. Third, the article explains why Suits' theory of games establishes the conceptual bases for developing what we could call a philosophy of PE oriented toward the game as an object. Finally, an example is provided of how this philosophy can guide the PE practice.
\end{abstract}

\section{KEYWORDS}

Physical education; philosophy; game; Suits; object-oriented philosophy

\section{Introduction}

Much has been said about Bernard Suits' theory of games from the field of sport philosophy, but little from the philosophy of physical education (PE) (García-Puchades and Chiva-Bartoll 2018). However, as this article will show, Suits' response to the problems arising from the definition of play, game and sport (Suits 1978, 1984, 2012, 2013) allows us to reflect anew on the philosophy of $P E$, providing further arguments for the pedagogical potential of the game (Kretchmar 1997, 2008; Loland 2002).

When observing the tradition of the philosophy of PE from the educational perspective proposed by Biesta (2010), it could be said that its theories have tried to justify the presence of games in schools based mainly on their socialization and qualification functions. Regarding its socialization justifications, games are instruments for social integration, whereas from the qualification perspective, they are means to develop the human being's essential capabilities in order to live a worthwhile life. However, we can

CONTACT Wenceslao Garcia-Puchades Wenceslao.Garcia@uv.es Eacultat de Magisteri, Didactica Expresión Musical, Plastica y Corporal, Universitat de Valencia, Av. dels Tarongers, 4, Valencia 46022, Spain 
also affirm that these justifications have left aside the capacity for subjectification of games (Biesta 2010, 20). From the perspective of subjectification, games should be understood not only as instruments capable of developing skills or abilities, but also capable of favouring situations in which the individual is impelled to be responsible for his/her own actions, as a consequence of the interruption of conventional knowledge (Garcia-Puchades and Chiva-Bartoll 2018).

The following text aims to open up new fields of application of Bernard Suits' theory of games. Our intention is not to enter into discussions about his ideas but to argue to what extent Suits' theory of games, when contemplated from the point of view of the Object-Oriented Philosophy (OOP) developed by Harman (2018), allows us to draw a first approximation of what could be called a philosophy of PE oriented toward the game as an object. OOP not only presupposes the existence of objects-in-themselves, but it also considers that this presupposition implies that there is no definitive or exhaustive characterization of them. As we will try to argue in this text, this philosophy could help us to establish the theoretical basis for developing a justification of games in the school setting based on its capacity for subjectification that complements the discourses of socialization and qualification.

The article is structured as follows. Firstly, we describe the dominant justifications of games following Biesta's education theory. Secondly, we explain how OOP could complement these justifications. Thirdly, we explain how Suits' theory of games establishes the conceptual basis for developing a philosophy of PE oriented toward the game as an object. Finally, an example of how this philosophy can guide the practice of PE is given.

\section{The Instrumentalist Justification for Games in the Philosophy of PE}

The concept of games has had a long history within the western educational philosophical discourse. If we focus on the dominant liberal paradigm of the $20^{\text {th }}$ century, education had to do basically with the development of rationality. For this reason, since games were not considered relevant to the improvement of rationality, they were relegated to a secondary position in the curriculum (Conant 1963; Hirst 1974; Hirst and Peters 1970; Lawson 1984; Peters 1966). However, many philosophers of PE have tried to justify games within educational institutions. The result has been a variety of theories that have tended to defend the multifaceted, paradoxical, and elusive nature of games. In some way, reflection on the role of games has been addressed by different traditions and practical orientations within the philosophy of PE (Stolz 2014, 17-24). In our opinion, it is possible to classify these discourses based on two of the functions that dominate contemporary educational practice: socialization and qualification (Biesta 2010, 19-22).

Socialization is one of the fundamental functions of education, and it has to do with the many ways education allows citizens 'to become part of a particular social, cultural, or political order' (Biesta 2010, 20). This function is found in many educational justifications for games. According to Devís (2008, 80-81), games as socializing elements have gained strength as an educational practice directed toward character formation in the last two centuries. On the question of how games and sports are connected to social values, there are two possible understandings: internalism, which claims that games and sports have their own intrinsic values, and externalism, which considers that values in sports reflect those of society (Simon 2007, 2015). Although Simon's internalism considers sport as a place in which 
humans can flourish, which ties the practice of sport to virtues and values in the larger society, the role of socialization of games lies mainly in the values attributed to games in the social context (Russell 2007). Not in vain, Ashworth (1971) and McIntosh (1979) had already mentioned the ideal of justice of games (and of sports) as one of the social values of the moment, proposing that it is merely a symbolic reflection of social life. In this vein, McNamee (2008), influenced by the Aristotelian ethic, understands the values of games as a collection of virtues that transcend the practice itself and are able to guide other social situations.

The function of qualification lies in the way education provides children and young people 'with knowledge, skills and understandings and often also with the dispositions and forms of judgment "to do something"' (Biesta 2010, 19). For Devís (2008), some objectives strongly emerge in this function, such as children's correct physical development, learning about hygiene based on the acquisition of healthy habits, and the compensatory function of physical activity. As an example, some studies have found evidence of cognitive, physical, moral, and emotional development in early childhood learning through games (Broadhead and Burt 2012). Another type of qualifying justification for games in the curriculum can be found in theories that defend their contribution to the students' aesthetic education (Da Costa and Oliveira 2016; Hein 1968), practical rationality in movement (Anderson 2002; Arnold 1979; Connolly 2008; Stolz 2013), and recreation (Dumazedier 1974).

In summary, the qualifying justifications share a similar substrate with the socializers, that is, the conception of games as instruments. For both types of discourse, games would be considered as a useful means to achieve a set of measurable learning outcomes. This set of outcomes is related to a priori knowledge that allows us to evaluate the educational value of games according to their impact. This allows us to make a planned use of games depending on our curricular needs (Biesta 2010). Below, we present a non-instrumental justification for games in the curriculum. The educational value of this justification is based not on the knowledge of a set of learning outcomes, but on the exploration of the different possibilities when playing a game.

\section{A Justification Oriented toward the Game as an Object}

For Biesta $(2018,14)$, education should not merely be aimed at producing 'a narrow set of outcomes', but it must 'provide opportunities for children and young people to express themselves, that is, to appear as individuals "in the world" and "with the world". In other words, education should not simply contribute to qualification and socialization, "but also impact on what we might refer to as individuation or, as I [Biesta] prefer to call it, subjectification, the process of becoming a subject" (Biesta (2010, 20). Taking Levinas' existentialism as a reference, Biesta $(2013,21)$ affirms that subjectivity 'emerges' in certain situations as a consequence of the encounter with 'the Other', which is a 'domain' that lies beyond conventional knowledge. Only on these occasions 'I cannot be replaced or substituted by someone else', therefore I am completely 'responsible' for my action. According to Biesta $(2013,105)$, we should view the subjectification of an individual experience as 'a new beginning', as an act of radical creativity in and with the world. In the absence of knowledge to turn to, individuals can only turn to themselves to seek new possibilities for action, to relate to the world around them and find new meanings. 
Subjectivity cannot be planned, since it is not something that we have or know. In this sense, Biesta's subjectification resembles the concept of creation theorized by Collingwood (1938) in his theory of art. For this author, creators do not produce something technically because they have not been acting in order to achieve any further end or following a preconceived plan (Collingwood 1938, 128-9). In this vein, Biesta (2010) affirms that the function of subjectification, unlike socialization and qualification, is not an instrumental one, since it is not linked to any a priori knowledge that allows us to plan its educational use in order to achieve desirable and measurable outcomes. Subjectivity 'is something that can be realized, from time to time, in always new, open, and unpredictable situations of encounters' (Biesta 2013, 12). In this sense, although teachers cannot force or plan students' subjectification, they can try to make it more likely to happen (Biesta 2013, 22). Keeping education open to the 'event of subjectivity' requires a pedagogy of interruption, that is, 'a pedagogy that aims to keep the possibility of interruptions of the normal order open' (Biesta 2010,90). To this end, the teacher could use different communicative strategies to 'shake' their students' beliefs and presuppositions 'in a deconstructive way'. This 'communication in deconstruction' supposes 'an affirmation of an otherness that is always to come': a participative, open and generative communicative process by which the teacher gets the students to ask and reflect on certain theories, assumptions and expectations (Biesta 2013, 38, 41, 42).

In our opinion, the task of deconstructing our assumed knowledge underlies the OOP developed by Harman (2002). However, as we will show in the next section, unlike Biesta's assertions, this task is always linked to objects (Harman 2011, 2018). OOP proposes different operations to question our knowledge about objects in order to present their particular otherness, or what Kant (1998) called its noumenal component, that is, the object-in-itself. In this sense, approaching Harman's OOP through Biesta's theory of education offers us the possibility of justifying the educational value of objects in general, and games in particular, in a non-instrumental way. Hence, before developing what could be considered a justification of games in the school setting based on its capacity for subjectification, we will briefly outline what OOP is and what operations it proposes to present the objects' internal otherness.

\section{Object-Oriented Philosophy}

OOP (also known as Object-Oriented Ontology) dates from the late 1990s, although it becomes best known as one of the four currents emerging from the so-called Speculative Realism in the late 2000s. Speculative Realism is a term that was coined at a conference held at Goldsmiths College, University of London, in April 2007. It involved Ray Brassier, lain Hamilton Grant, Graham Harman and Quentin Meillassoux (Brassier et al. 2007). All of them struggled against a common enemy: correlationism. For correlationism, whose origin they locate in Kantian philosophy, as human beings, we cannot grasp the world as it is 'in itself' (the noumenal) in isolation from its relationship with the world as it is 'for us' (the phenomenal). On the other hand, Speculative Realism insists that the world exists 'in itself' and we can speculate about it (Gratton 2014). In this regard, Harman $(2012,17)$ considers that Kant's mistake is to 'hold that the relation of appearance to the in-itself is an all-or-nothing affair', that is, since the things-in-themselves cannot be made present, we are restricted to discussions of the conditions of human experience. Indeed, there are different artistic and literary operations 
that show us that the fact we are not able to directly present the things-in-themselves does not forbid us from having indirect access to them (Harman 2012, 17; 2018, 58-101).

Graham Harman's OOP, unlike the rest of the founders of Speculative Realism, recovers the fascination with objects in a provocative way. Taking its foundations from Heideggerian phenomenology combined with Bruno Latour's ANT (Action Network Theory), Zubiri's metaphysics and Ortega's aesthetics, OOP is sustained in a radical and imaginative ontology that not only affirms that objects (whether they be human, nonhuman, natural, cultural, real or fictional) exist beyond the purview of human conception, but also that this existence is not directly accessible from the way we normally experience them (Harman 2018, 9). The task of OOP is to account for this gap between the sensual and the real dimension of an object, showing that the inexhaustible way in which an object is normally presented to us does not exhaust the real object (Harman 2018).

In order to do it, we must bring to light four types of tensions that exist due to the intersection of two axes (real/sensual and object/qualities): space, time, eidos, essence (Harman 2011, 99-102). Showing its time, we verify that an object is less than its accidental or sensual qualities, and its superfluous additions can be withdrawn without the object itself being harmed (Harman 2011, 23, 100). With its eidos, we verify that an object will never be completely presented through its real qualities, which are theoretical abstractions only accessible through the intellect, since we can always add a new one (Harman 2011, 27-28). Presenting its space, we are aware of the immeasurable system that relates its elements according to a specific function (Harman 2011, 38-39). Finally, by showing its essence, we know that even though the object seems to need its real qualities to exist, they are not the object itself. Every essence necessarily withdraws both from other essences and from itself; therefore, it lies beyond any possible characterization (Harman 2011, 104-105). These four types of tensions create a scheme of sameness and difference inside an object that explains the infinite possibilities to interpret it without exhausting it (Wolfendale 2014).

However, these tensions do not show anything about how genuine changes are produced in an object. To explain these changes, it is necessary to understand how these tensions are broken. In this regard, Harman (2011, 102-107) talks about four types of fundamental operations: confrontation, theory, allure and causation. We encounter confrontation as a rupture of the time of an object. Through confrontation we realise that sometimes the sensual qualities deceive us, and what seemed to be one thing finally turns out to be another (Harman 2011, 103). As a rupture of eidos, theory shows that the real qualities that once characterized an object could change (Harman 2011, 104). Allure, as a rupture in the space of an object, makes us aware that sometimes other functions, and with them other relational systems, can appear beyond the ordinary ones (Harman 2011, 103). Causation, by breaking its essence, allows us to imagine what an object would be like if we speculated about possible real qualities that have not been known yet (Harman 2011, 105).

Finally, what these tensions and ruptures prove is that the different ways to interpret or transform an object do not exhaust the object itself. This allows OOP to justify the difference between the object itself and the object related to us. In doing so, this philosophy attributes to the object a space of uncertainty that is worthy of being examined for its own sake, that is, a thing of wonder (Bogost 2012, 129). As we have shown above, it allows us to think about an educational use of OOP applied to games. In our opinion, these tensions and ruptures 
could be interpreted as deconstruction strategies that PE teachers could use to make their students question the familiar way to play games. Furthermore, by inviting their students to go beyond their conventional relationship with games, an interesting proposal could be to bring Biesta's idea of subjectification to PE practice. PE teachers could learn from OOP how to encourage students to explore the game rather than simply plucking the already 'known' answer from them or the text. In other words, OOP offers some ideas to use games not only in terms of their impact on learning outcomes but also the idea of the game for the game's sake. Later we will try to apply these strategies to the learning process of games. For now, we will try to justify to what extent it is possible to interpret Suits' theory of games from the OOP.

\section{The Orientation toward the Object in Bernard Suits' Theory of Games}

Complementing the traditional philosophical tendencies of PE focused on intensifying the relational dimension of games, the philosophy of PE oriented toward objects would explore games as objects-in-themselves by highlighting their tensions and ruptures. However, how could they be accessed if they are set apart from every ordinary relationship? They could be accessed through game-playing, that is, through games as objectsfor-us.

In our opinion, Suits' theory of games supports this idea. Below we will try to argue to what extent Suits offers us the possibility of exploring the inscrutable reality of games through his definition of 'playing a game' (or what we will call 'a ludic practice') as an exploration of the infinite relational possibilities of its components according to an intrinsic finality. When playing, the player is not only able to interpret its elements, giving rise to different actions, but $s /$ he is also capable of transforming them, looking for new challenges. For Suits, playing a game does not use up the game's possibilities. An infinite number of ways can always be found to play a game and we cannot say which is the real one. We will look at these arguments in greater detail.

\section{The Game as an Intentional Object: The Ludic Practice}

Bernard Suits (1978) is a philosopher of reference in the reflection on the meaning of games and, in spite of objections to his definition of playing, his works are an excellent catalyzer of later philosophical debates (Hurka 2006; Kretchmar 2006; Mcbride 1979; Meier 1988; Thompson 2004, to name some of them). One of the fundamental aspects of Suits' work is the idea that any comprehension of a game must be explored through what it means to play a game.

To play a game is to attempt to achieve a specific state of affairs [prelusory goal], using only means permitted by rules [lusory means], where the rules prohibit use of more efficient in favour of less efficient means [constitutive rules], and where the rules are accepted just because they make possible such activity [lusory attitude]. (Suits 1978, 41)

In his definition, Suits shows the four conditions of game playing. Although each of the four conditions is a necessary (but no sufficient) condition to be a case of game playing, the four of them taken together (as a unified formula) are a sufficient condition for any 
instance of game playing (Kobiela 2016, 18; Suits 1978, 35). The prelusory goal indicates the objective of a particular game. The only requirement of the prelusory goal is that it is self-referential, so it does not make sense or have any relevance outside the game itself (Huang and Ryall 2018, 83). The lusory means specify how the goal can be reached, and they are inherently inefficient. They reveal a distinction from work, where the means used must be efficient in order to reach the goal. The lusory means are regulated by rules that specify how the game can be played. The constitutive rules prohibit the most efficient way to reach the goal. This is directly analogous with Caillois (1961), for whom ludus, unlike the anarchic and free game (paidia), introduces 'taste for gratuitous difficulty'. This idea is highlighted by Hurka (2006, 227), who nuances the original Suits' definition of lusory attitude by stating that a player would accept the rules 'not just because they make the game possible, but also because they make it difficult'. Thus, for Hurka $(2006,227)$, while the rules, the means, and the prelusory goal make the game a valuable activity by introducing an intrinsic difficulty, the lusory attitude chooses it because of this feature. Besides 'if something is intrinsically good, the positive attitude of loving it for the property that makes it good, that is, desiring, pursuing and taking pleasure in that for that property, is also, and separately, intrinsically good' (Hurka 2006, 227-8). Finally, to play a well-formed game, it is necessary to assure that the level of difficulty at the time of achieving that goal pursued is motivating enough to attempt the challenge, but also to accept that players could fail if they do not make an effort: 'An impossible game is not worth playing, while a goal that is too easy becomes boring' (Huang and Ryall 2018, 90).

Therefore, we see how the lusory attitude converts the relationship with the game into a special situation. Salen and Zimmerman $(2003,96)$ relate to this special situation using the term the magic circle. In its interior, 'a new reality is created, defined by the rules of the game and inhabited by its players'. The result would be a space unified by the player's intention to find it valuable to explore the possible means for resolving the challenge. However, for Suits, there are other types of games, such as make-believe games, that make us question the closed nature of this intentional space. In this type of game, situations arise where the players can adapt its different elements in order to keep the game alive. Thus, Suits $(1978,133)$ adapts his definition of game-playing in order to include these open-ended practices.

\section{The Open-Ended Ludic Practice}

According to Suits $(1978,133)$ an open-ended ludic practice has the challenge of prolonging the game for as long as possible. In order to achieve this, players must adopt an attitude aimed at maximizing their 'role-performances" (1978, 112, 125, 135). According to this attitude, a player's performance would be successful if it evokes new responses $(1978,125)$. Thus, with the intention of keeping the game alive and evoking more responses, the players can accept the end, the means, and the rules with greater flexibility. This attitude differs from the goal-oriented attitude adopted by the players in closed ludic practices. In the latter, the players define a challenge as a state of affairs to achieve and some rules to follow, and so it is clear when the game ends. One might think that more rule-based games would be associated with closed practices, and less rule-based games with more open practices. However, for Suits $(1978,136)$, both types of games are more or less open practices. 
From our point of view, the open-ended attitude would indicate the degree of flexibility a player accepts when playing and, therefore, the degree of uncertainty she is willing to accept. Uncertainty is fundamental in the progression of a game, and it is experienced in the interior of the intentional space of the game as a conflict with its components. The multiple situations that can arise in a game are unpredictable. Malaby (2007) relates this unpredictability of games to their capacity to generate meanings and, therefore, to the interpretability of their elements. 'Interpretability' is what keeps the game going, the desire to discover what is going to happen (Bateman 2011, 48). The open-ended nature of the ludic practice forces the player to interpret its components according to the uncertainty s/he is willing to accept regarding: the prelusory goal, defining the challenge as a state of affairs to achieve or maximizing 'role-performance'; the constitutive rules, adopting a flexible attitude in pursuit of a longer or shorter game; the lusory means, accepting a way to resolve a challenge or searching for different alternatives; the lusory attitude, valuing the necessary difficulty of a challenge to maintain the motivation.

Players can discover numerous ways to solve a challenge, by interpreting its objectives, rules, means, and difficulties in different ways, but they cannot say that any of them is the genuine one. Therefore, in the same way that OOP brings to light the intrinsic tensions of an object to show that the object is something more than what we can say about it, the different ways in which one player overcomes a challenge by interpreting its elements shows that a game is something more than the set of possible solutions to this challenge. We will develop this idea in the following section.

Until now, we have talked about how changes occur in the game without transforming any of its elements. Any type of change in a ludic practice occurs on the plane of the players' interpretation, due to the uncertainty of its components. However, the ludic practice can change showing a substantial transformation in its components. For example, as Suits states, it is possible to play a game even though the rules or the means can be changed in order to 'heighten the difficulties they [players] are required to overcome' (Suits 1978, 38). The transformation of the challenge creates a conflict in the persistence of the intentional space of a game to the degree that is presented as a radically different experience. However, the essence of the game remains beyond this transformation. In these situations, just as OOP highlights the intrinsic ruptures in the capacity of causation of an object to show that its essence is something more than the set of different possibilities of using it, the chance of choosing different challenges within a game could be understood as its essence, that is, the inexhaustible source of transformation of a ludic practice. In other words, a ludic practice does not exhaust the game, because a player can always find a new challenge to overcome. Therefore, in the same way that OOP affirms that a real object is a withdrawal from our way of experiencing it, we can understand the game in Suits' theory as that which is a withdrawal from our ludic practice. Thus, whereas a ludic practice is one of the many ways of executing a game (the intention to overcome a difficult enough challenge by accepting some rules and according to some means), the game is what is always withdrawn from any execution, since the player can always find new challenges that make this practice different. This conception of the game would coincide with that of Malaby (2009), who states that the game is merely a form of contrived contingency created with the intention of being open to interpretation. Taking this idea as a reference, we could affirm that the game is 
a contingent or uncertain reality, and a ludic practice is the interpretation of this contingency by the player through a lusory attitude.

However, the distance that separates the game from playing is permeable (Bogost 2012; Castronova 2005). This distance is what allows the player to explore new challenges and modify the rules, without varying the essence of the game. Therefore, the game inspires the players' natural curiosity and motivates them to explore countless operations to overcome different challenges (Bogost 2012, 54). To that extent, just as OOP does with objects, Suits' theory of games allows us to attribute the property of astonishing to the game.

Furthermore, the distinction between game and ludic practice offers the chance to view the conflict between the static nature of the intrinsic properties and values of the game and the dynamic nature of the reasons why an individual approaches it, without it implying renouncing to the autotelic nature of the game (Schmid 2011, 156-157). The lusory attitude of the player in considering the intrinsic properties of such activity as valuable, does not exhaust all possibilities of experiencing a game. An individual can use the game for other reasons than the merely intrinsic ones, that is, finding valuable the prestige that derives from it, or the opportunity of meeting other individuals, 'without that [lusory] attitude somehow being destroyed or contaminated by such an association' (Suits 1978, 144). We believe that the inscrutable excess that separates the game from playing a game allows Suits to think of the existence of a more complex practice that makes compatible the autotelic experience of the game and the non-autotelic one. In this regard, according to Morgan (2015) it is possible to understand Suits $(1978,145)$ when he states that playing a game is not exclusive to amateurs. A player accepts the rules of the game 'just because such acceptance makes possible such activity', but that does not mean that it is 'the only reason he may have' (Suits 1978, 144). In this sense, the professional player can play a game in spite of being paid for that. As Huang and Ryall $(2018,84)$ point out: 'The fact that one is paid can be considered alongside other auxiliary goals or motivations for engaging in games, such as being sociable, getting fit, or raising money for charity'.

In synthesis, Suits' theory of games offers the possibility of developing a philosophy oriented toward the game as an object. In fact, by introducing open-ended ludic practices in his definition of the game, he also introduces an insurmountable distance between the game itself and the game played. This distance is presented in two ways. On the one hand, the game is shown to be excessive with regard to the interpretation of its elements according to a challenge. On the other hand, the game exceeds the transformation of its elements in order to modify the challenge without jeopardising its identity. In our opinion, by contemplating these two ways of presenting the excess between the game itself and the game played in terms of the tensions and ruptures proposed by OOP, we are able to develop the basis for a philosophy of PE oriented toward the game as an object.

\section{Basis for a Philosophy of PE Oriented Toward the Game as an Object: Exploration of its Inscrutable Reality}

Based on OOP, we have shown the degree to which Suits' theory supports the idea that the inscrutable reality of a game turns the ludic practice into a space capable of 
surprising and intrinsically motivating curiosity in players. They experience this space by exploring the different possibilities to interpret and transform its parts to overcome a challenge and to generate new ones. We recall that for Harman's OOP, the exploration of what is hidden in an object was based on four types of tensions (time, eidos, space, and essence) and four types of ruptures (confrontation, theory, allure and causation). We will see to what extent we can apply these considerations to the game philosophy elaborated by Suits.

For Suits, one of the ways to explore the inscrutable reality of a game is by 'playing a game'. To do so, it is necessary to adopt a lusory attitude. As we have argued above, this attitude is compatible with other attitudes, but it is only necessary to play the game. The lusory attitude offers the game a presence as ludic practice: an intentional or sensual object that unifies the possible relationships among its elements (lusory means) based on some constitutive rules and with an intrinsic purpose (prelusory goal). This object would establish a space where the actions performed to overcome the challenge would be established. This relational space would remain hidden to the player, and it would only have presence as a break with the established challenge. When the difficulty of the challenge is not sufficiently motivating, the ludic practice become an object of explicit attention.

In addition, the different actions performed in a relational space would represent the accidental traits of the game, just as the player experiences them. The tension between the unit of the game experienced and the progression of the actions performed would receive, according to the terminology developed by Harman, the name of time. The time within the game would indicate the tension between stability and change, that is, the variability of the actions within the integrity of a relational space determined by a challenge.

During the game, players synthesize the variability of their actions in facing a challenge, establishing different regularities. They are theoretical abstractions that offer different performance models or strategies that guide the player. Unlike the possible actions to resolve a challenge, the performance models would point to the real features or qualities of the ludic practice. However, like the accidental features, the real features do not use up the intentional object. It is always possible to find new strategies that orient us in the game. The tension between the multiple performance models and the unit of the game experienced as ludic practice would receive the name of eidos.

However, when playing, it is possible to direct actions according to strategies that are not generated through intuition, but rather through deduction or speculation. This situation would produce a fourth tension with the game in so far as it is considered an object withdrawn from its accidental features. This tension is called essence. The essential features grant identity to the game apart from the experience.

These four tensions represent the way a player explores the constancy and variability within a ludic practice. However, they do not show how radical transformations are produced in it. Thus, it is necessary to explore how these tensions are broken. Confrontation would mean a rupture with the time of a game, for example, as a consequence of a confusion when interpreting a challenge and trying to resolve it through a series of actions. This operation would break the continuity of the actions performed to face the challenge. Contrasting would appear as a rupture with the eidos of a game. This would occur when the player theoretically rethinks the strategy that had been used until that moment to orient his/her ludic practice. The operation of fusion would occur as allure with regard to the space and as causation with 
regard to the essence. The allure would be produced, as mentioned above, when relational space generated by the lusory attitude is questioned when accepting a challenge. The lack of difficulty of a challenge obligates the player to create a new space by transforming some of the elements of the game and, thus, exploring what remains hidden to the practice itself, the real game, which exists apart from experience and is the source of new possibilities. Finally, causation occurs as a break with the essential features of a game. This operation is closely linked to allure because it is necessary to look at the real game to find new strategies that guide its actions.

\section{Application of the Theory of Games to a Typical PE Game}

In order to exemplify this proposal, we will explain it using the typical PE game ' 5 catch'. The PE teacher could adopt an attitude oriented toward the game as a socialization and qualification instrument, and thus justify its presence in his/her classes due to its extrinsic values: the game teaches teamwork, the students develop their physical condition and their coordination, etc. However, the teacher could also adopt an attitude oriented toward the game as an object, and try to make his/her students find it valuable to explore its inscrutable reality. The game of '5 catch', disconnected from any external relationship, has an autonomous and mysterious reality. To this end, the teacher must favour the encounter with its capacity to provoke wonder by showing that there are infinite possibilities to solve a challenge and to transform its elements by generating new challenges. As we have seen, one way to do this is through the ludic practice. Among all the possibilities for playing this game, the teacher would choose one. A relational space to carry out possible actions according to a challenge (an intrinsic goal with a certain difficulty): manage to execute 5 passes in a row among the members of a same team; a set of rules: two teams of six players each, a space measuring $20 \times 20 \mathrm{~m}$ and a basketball. The students begin to play by exploring the infinite possibilities to overcome a challenge through different actions. During the game, the teacher could contribute to getting the students to reflect on these actions, bringing to light their strategies, which would represent the tactics of the game. In addition, the teacher could also encourage them to elaborate other strategies in a speculative way: 'And if we move in a straight line?' This act of speculation about the playing tactics would involve a reflection about the essence of the ' 5 catch' game. However, as the playing time evolves, the players might find that the proposed challenge is not difficult enough. Its time runs out, the game gradually becomes boring. The teacher asks the students to think about transforming the game (Suits 1978, 30). To do so, s/he can ask the players: 'How can we make the game more difficult?' The student is attracted by the part of the game that remains hidden: 'We can reduce the space', 'increase the number of steps' etc. By transforming the challenge and the rules, the relational space of the game is renewed. It is a question of enacting, of executing, the game again without it losing its identity. Again, the players must try to resolve the proposed challenge. To do so, the previously learned actions may not be useful, and they may have to create other new ones, confronting them or contrasting them with the tactics that were useful before to orient their practice. Finally, the teacher can suggest that the students speculate about new strategies that would cause other ways of orienting their ludic practice. 


\section{Conclusions}

Based on Suits' theory of games, Biesta's theory of education and Harman's OOP, the article makes a first approach to a philosophy of PE oriented toward the game as an object. In it, the theoretical bases are established for a justification of games in the school setting. In our opinion, this philosophy provides a justification of games based on their capacity for subjectification that complements the discourses of socialization and qualification. The philosophy of PE oriented toward the games as an object is developed as a theory whose intention is to use games to make students experience themselves as subjects of a new beginning: an act of radical creativity in which they can experience their individuality as a way of relating to the environment in a unique way. As we argued, this is not something that teachers can plan or give to their students. However, teachers can increase the chances for their students to experience it by carrying out an open and participatory process to deconstruct their students' beliefs and assumptions about games. The philosophy offers the teacher different strategies to conduct this process. They could interpret and transform the conventional objectives, rules, means and difficulties of a game to challenge known tactics and skills, that is, the normal way in which a game is played. By showing their students that there are different possible ways of playing a game without losing its essence, teachers can show that the game itself is indescribable and inexhaustible. This opens up different possibilities to consider 'strange' new ways of relating to it. In this way, they leave the learning process of a game open for an act of radical creativity in which they experience their own individuality. To achieve this, teachers can propose that students interpret and transform the game's objectives, means, rules and difficulties in different ways. By offering students opportunities to give their own meaning to their ludic practices, teachers will also give them the chance to express for themselves what makes them unique, that is, their own subjectivity (Biesta 2010, 2013).

The experience of the ludic practice is lived intentionally as a predisposition to openness (Hyland 1980). It becomes a space capable of astonishing, producing surprises and novelties. Exploring this space of uncertainty is something worth considering for its own sake, a thing of wonder (Bogost 2012, 129). Through the philosophy of PE oriented toward the game as an object, game becomes an unconditional and autotelic activity. The player's commitment is not to use it as an instrument to achieve an external goal, but rather to play it as an end in itself. The curricular justification for games as objects contemplates the ludic practice as a valuable object in itself. In a game, the acceptance of our possibilities and limitations would only be applicable to the activity itself (Mclaughlin and Kretchmar 2008). From this perspective, any type of justification would have nothing to do with the instrumentalist postures mentioned.

\section{Disclosure statement}

No potential conflict of interest was reported by the authors.

\section{ORCID}

Wenceslao Garcia-Puchades (ID http://orcid.org/0000-0002-0919-9816

Oscar Chiva-Bartoll (D) http://orcid.org/0000-0001-7128-3560 


\section{References}

ANDERSON, D. 2002. The humanity of movement or 'It's not just a gym class'. Quest 54 (2): 87-96. doi:10.1080/00336297.2002.10491768

ARNOLD, P. 1979. Meaning in movement, sport and physical education. London, UK: Heinemann.

ASHWORTH, C.E. 1971. Sport as a symbolic dialogue. In The sociology of sport: A selection of readings, edited by E. Dunning. London: Frank Cass: 40-46.

BATEMAN, C. 2011. Imaginary games. Winchester: Zero Books.

BIESTA, G. 2010. Good education in an age of measurement: Ethics, politics, democracy. Boulder:

Paradigm Publishers.

BIESTA, G. 2013. The beautiful risk of education. London: Routledge.

BIESTA, G. 2018. What if? Art education beyond expression and creativity. In Art, Artists and Pedagogy.

Philosophy and the Arts in Education, edited by C. Naughton, G. Biesta, and D. Cole. London:

Routledge: 11-20.

BOGOST, I. 2012. Alien phenomenology or what it's like to be a thing. London: University of Minnesota

Press.

BRASSIER, R., I.H. GRANT, G. HARMAN, and Q. MelLLASSOUX 2007. Speculative realism. Collapse 3: 306-449.

BROADHEAD, P. and A. BURT. 2012. Understanding young children's learning through play. New York:

Routledge.

CAILLOIS, R. 1961. Man, play and games. Urbana \& Chicago: University of Illinois Press.

CASTRONOVA, E. 2005. Synthetic worlds: The business and culture of online games. Chicago: University of

Chicago Press.

COLLINGWOOD, R.G. 1938. The principles of art. New York: Oxford University Press.

CONANT, J.B. 1963. The education of American teachers. New York: McGraw-Hill.

CONNOLLY, M. 2008. The remarkable logic of autism: Developing and describing an embedded

curriculum based in semiotic phenomenology. Sport, Ethics and Philosophy 2 (2): 234-56.

doi:10.1080/17511320802223824

DA COSTA, L.A. and T. OLIVEIRA. 2016. On the aesthetic potential of sports and physical education. Sport,

Ethics and Philosophy 10 (4): 444-64. doi:10.1080/17511321.2016.1210209

DEVis, J. 2008. El juego en el currículum de la EF: Aproximación crítica (o el reino de lo posible en la

postmodernidad. Revista EF Y Deporte 27 (2): 79-89.

DUMAZEDIER, J. 1974. Sociology of leisure. Amsterdam: Elsevier.

GARCIA-PUCHADES, W. and O. CHIVA-BARTOLL. 2018. El juego como proceso de subjetivación en educación

física y su justificación curricular. Cultura, Ciencia Y Deporte 38 (13): 147-56.

GRATTON, P. 2014. Speculative realism. problems and prospects. London: Bloomsbury.

HARMAN, G. 2002. Tool-being. Chicago: Open Court.

HARMAN, G. 2011. The quadruple object. Winchester, UK: Zero Books.

HARMAN, G. 2012. Weird realism: Lovecraft and philosophy. Winchester, UK: Zero Books.

haRMAN, G. 2018. Object-oriented ontology: A new theory of everything. London: Penguin Books.

HEIN, H. 1968. Play as an aesthetic concept. The Journal of Aesthetics and Art Criticism 27 (1): 67-71.

doi:10.2307/428530

HIRST, P.H. 1974. Knowledge and the curriculum. London: Routledge \& Kegan Paul.

HIRST, P.H. and R.S. PETERS. 1970. The logic of education. London: Routledge \& Kegan Paul.

HUANG, Y. and E. RYALL. 2018. On the relationship between philosophy and game-playing. In The

philosophy of play as life, edited by W. Russell, E. Ryall, and M. MacLean. London: Routledge: 80-93.

HURKA, T. 2006. Games and the good. Proceedings of the Aristotelian Society 106 (1): 217-35. doi:10.1111/j.0066-7373.2006.00132.x

HYLAND, D.A. 1980. The stance of play. Journal of the Philosophy of Sport 7: 87-99. doi:10.1080/ 00948705.1980.9714370

KANT, I. 1998. Critique of pure reason. Translated by Paul Guyer \& Allen W. Wood. Cambridge: Cambridge University-Press.

KOBIELA, F. 2016. The goal triad in games. A conceptual map and case studies. Recerca, Revista De

Pensament I Anàlisi 18: 13-27. doi:10.6035/Recerca 
KRETCHMAR, R.S. 1997. Philosophy of sport. In The history of exercise and sport science, edited by J.

D. Masssengale and R. Seanson. United States of America: Human Kinetics: 181-203.

KRETCHMAR, R.S. 2006. The intelligibility of suits's utopia: The view from anthropological philosophy'.

Journal of the Philosophy of Sport 33 (1): 67-77. doi:10.1080/00948705.2006.9714691

KRETCHMAR, R.S. 2008. Gaming up life: Considerations for game expansions. Journal of the Philosophy

of Sport 35 (2): 142-55. doi:10.1080/00948705.2008.9714735

LAWSON, H.A. 1984. Invitation to physical education. Champaign: Human Kinetics.

LOLAND, s. 2002. Fair play in sport: A moral norm system. London: Routledge.

MALABY, T.M. 2007. Beyond play: A new approach to games. Games and Culture 2 (2): 95-113. doi:10.1177/1555412007299434

MALABY, T.M. 2009. Anthropology and play: The contours of playful experience. New Literary History 40 (1): 205-18. doi:10.1353/nlh.0.0079

MCBRIDE, F. 1979. A critique of Mr. Suits' definition of game playing. Journal of the Philosophy of Sport

4: 59-65. doi:10.1080/00948705.1979.10654151

MCINTOSH, P.C. 1979. Fair Play: Ethics in sport and education. London: Heineman.

MCLAUGHLIN, D.W. and R.S. KRETCHMAR 2008. Reinventing the wheel: on games and the good life. Doctoral thesis, Pennsylvania State University.

MCNAMEE, M. 2008. Sports, virtues and vices: Morality plays. Abingdon: Routledge.

MEIER, K.V. 1988. Triad trickery: Playing with sport and games. Journal of the Philosophy of Sport 15:

11-30. doi:10.1080/00948705.1988.9714458

MORGAN, W.J. 2015. On suits on the moral normativity of games. Unpublished manuscript presented

in Games, Play, and Sports: After Suits, University of Toronto. Available at: https://www.huma

nities.utoronto.ca/uploaded_files/content/1630/file/Morgan_On_Suits_on_Normativity_of_

Games.pdf (accessed 20 July 2018)

PETERS, R.S. 1966. Ethics and education. London: Allen \& Unwin.

RUSSELL, J.S. 2007. Broad internalism and the moral foundations of sport. In Ethics in sport, edited by

W. Morgan. Champaign: Human Kinetics: 51-66.

SALEN, K. and E. ZIMMERMAN. 2003. Rules of play: Game design fundamentals. Cambridge, MA: MIT Press. SCHMID, S.E. 2011. Beyond autotelic play. Journal of the Philosophy of Sport 38 (2): 149-66. doi:10.1080/00948705.2011.10510418

SIMON, R.L. 2007. Internalism and internal values in sport. In Ethics in sport, edited by W. Morgan. Champaign: Human Kinetics: 35-50.

SIMON, R.L. 2015. Internalism and sport. In Handbook of the philosophy of sport, edited by

M. McNamee and W.J. Morgan. New York: Routledge: 22-34.

Stolz, S.A. 2013. Phenomenology and physical education. Educational Philosophy and Theory 45 (9): 949-62. doi:10.1080/00131857.2013.785355

Stolz, S.A. 2014. The philosophy of physical education: A new perspective. London: Routledge Taylor and Francis.

sulTs, в. 1978. The grasshopper. Games, life and utopia. Toronto, Buffalo: University of Toronto Press. sUiTs, B. 1984. Games and utopia posthumous reflections. Simulation \& Gaming 15 (1): 5-24. doi:10.1177/0037550084151002

SUITS, B. 2012. Tricky triad: Games, play, and sport. Journal of the Philosophy of Sport 15 (1): 1-9. doi:10.1080/00948705.1988.9714457

sulTs, B. 2013. Words on play. Journal of the Philosophy of Sport 4 (1): 117-31. doi:10.1080/ 00948705.1977.10654132

THOMPSON, K. 2004. Sport and utopia. Journal of the Philosophy of Sport 31 (1): 60-63. doi:10.1080/ 00948705.2004.9714649

WOLFENDALE, P. 2014. Object-oriented philosophy. The noumenon's new clothes. Windsor Quarry: Urbanomic-Media-Ltd. 